\title{
Oxygen reduction catalyzed by nanocomposites based on graphene quantum dots-supported copper nanoparticles
}

\author{
Ke Liu, Yang Song, and Shaowei Chen* \\ Department of Chemistry and Biochemistry, University of California, 1156 High Street, Santa \\ Cruz, California 95064,USA.* E-mail: shaowei@ucsc.edu
}

\begin{abstract}
Nanocomposites based on graphene quantum dots (GQDs)-supported copper nanoparticles were prepared by thermal refluxing of copper salts in 1,2-propanediol at $140{ }^{\circ} \mathrm{C}$ in the presence of GQDs. Transmission electron microscopic measurements showed that the resulting $\mathrm{Cu} / \mathrm{GQD}$ nanoparticles increased from 5 to $15 \mathrm{~nm}$ in average diameter with increasing metal loadings. Raman spectroscopic measurements showed that all nanocomposites exhibited well-defined D and G vibrational bands. X-ray photoelectron spectroscopic studies indicated the formation of $\mathrm{Cu}_{2} \mathrm{O}$ and $\mathrm{CuO}$ in the nanocomposite particles, along with various defect concentrations within the GQD graphitic skeletons. Electrochemical studies showed that the nanocomposites exhibited apparent electrocatalytic activity in oxygen reduction in alkaline media, and the sample with a $\mathrm{Cu} / \mathrm{C}$ atomic ratio of $2.88 \%$ exhibited the best ORR activity among the series, within the context of onset potential, number of electron transfer and kinetic current density. The performance was further improved by deliberate hydrothermal treatments of the sample, and $160{ }^{\circ} \mathrm{C}$ was identified as the optimal temperature, which was ascribed to manipulation of the electronic interactions between copper nanoparticles and oxygen intermediates by the GQD structural defects.
\end{abstract}

Keywords: graphene quantum dots; copper nanoparticle; hydrothermal; defect; oxygen reduction 


\section{Introduction}

Oxygen reduction reactions (ORR) have long been regarded as a major bottleneck of the overall fuel cell performance, due to the sluggish electron-transfer kinetics and complex reaction pathways [1-3]. Therefore, extensive efforts have been devoted to the development of efficient catalysts so that sufficiently high current density can be achieved for practical applications. Towards this end, substrate-supported discrete nanoparticles have attracted particular attention. These include monometallic nanoparticles [4-7], alloy nanoparticles [8-10], metal oxides nanoparticles [11-15], and transition metal chalcogenide nanoparticles [16] that are supported on diverse substrates including metal structures [17], metal oxides [18], or carbon-based materials such as carbon black, standard carbon fibers [19], single- or multi-walled carbon nanotubes [20], and graphene sheets [21-24]. As summarized in several recent reviews [25-27], these supporting materials play important roles in, for instance, preventing nanoparticle aggregation and increasing the corresponding surface areas; manipulating electronic energy of the metal nanoparticles and hence interactions with $\mathrm{O}_{2}$ molecules via intimate electronic interactions with the supporting substrates; enhancing electronic conductivity and serving as current collectors; as well as improving structural stability of the catalysts in extreme acidic or basic environments.

Among these, Pt nanoparticles (diameter 2 to $4 \mathrm{~nm}$ ) supported on high-surface-area carbon black have been used extensively [28]. However, the high costs and scarcity of platinum render it necessary to develop cost-effective non-Pt substitutes for fuel cell electrocatalysis. Copper is inexpensive, abundant with excellent electronic conductivity. It has been reported that $\mathrm{O}_{2}$ molecules can adsorb readily onto and migrate on copper surfaces [29] and the adsorbed oxygen may undergo a two-step hydrogenation process to form gaseous water [30, 31]. ORR activities of bulk copper have also been observed in a borax buffer solution $[32,33]$ or in sulfuric 
acid solution [34], where the surface redox chemistry of $\mathrm{Cu}_{2} \mathrm{O} / \mathrm{CuO}$ plays an important role in the reduction of oxygen molecules. In a more recent study, reduced graphene oxide (RGO)supported cuprous oxide nanoparticles were found to serve as efficient catalysts for ORR where the mobile electrons in the graphene network can be supplied to $\mathrm{Cu}_{2} \mathrm{O}$ nanoparticles and then donated to oxygen [35]. However, graphene sheets usually exhibit irregular shapes and are prone to folding and wrinkling because of strong $\pi-\pi$ interactions leading to a loss of the surface area [36]. Such an issue may be minimized by using nanosized GQDs. For instance, platinum nanoparticles supported on GQDs (in the range of 1 to $4 \mathrm{~nm}$ ) have been reported to exhibit significantly enhanced catalytic activity towards ORR as compared to commercial Pt/C catalysts $[37,38]$. This was accounted for by the large surface-to-volume ratio and abundant structural defects of GQDs that manipulate the binding interactions of oxygen on Pt and hence facilitate the corresponding charge transfer process. Such a fundamental principle may be exploited for the design and engineering of effective ORR catalysts based on GQD-supported metal nanocomposites. This is the primary motivation of the present study.

Herein, we prepared GQD-supported copper nanoparticle composites and examined the ORR activity in alkaline media. Experimentally, the submicrometer domains of traditional pitchbased carbon fibers were broken down by acid treatments and chemical exfoliation, yielding nanometer-sized GQDs [39]. The GQDs were then used to prepare a series of $\mathrm{Cu} / \mathrm{GQD}$ nanocomposites at controlled copper loadings by thermolytic reduction of copper salts in 1,2propanediol, followed by hydrothermal treatments at various temperatures. The structural characteristics of the $\mathrm{Cu} / \mathrm{GQD}$ nanocomposites were carefully examined by transmission electron microscopic, Raman, and X-ray photoelectron measurements. Electrocatalytic activities of the nanocomposites were tested by rotating ring-disk electrode (RRDE) voltammetry. The $\mathrm{Cu} / \mathrm{GQD}$ 
nanocomposites at a $\mathrm{Cu} / \mathrm{C}$ atomic ratio of $2.88 \%$ showed the best performance among the series, which might be further improved by hydrothermal treatment to manipulate the GQD defect concentration, within the context of onset potential, number of electron transfer as well as kinetic current density.

\section{Experimental section}

\subsection{Chemicals.}

Cupric sulfate pentahydrate $\left(\mathrm{CuSO}_{4} \cdot 5 \mathrm{H}_{2} \mathrm{O}, \geq 98.0 \%\right.$, Fisher Scientific), sodium acetate trihydrate $\left(\mathrm{NaOAc} \cdot 3 \mathrm{H}_{2} \mathrm{O}, \mathrm{MC} \& \mathrm{~B}\right), 1,2$-propanediol (ACROS), pitch carbon fibers (Fiber Glast Development Corporation), sodium carbonate $\left(\mathrm{Na}_{2} \mathrm{CO}_{3}, \geq 99.5 \%\right.$, Sigma-Aldrich), sulfuric acid $\left(\mathrm{H}_{2} \mathrm{SO}_{4}\right.$, Fisher Scientific), and nitric acid $\left(\mathrm{HNO}_{3}\right.$, Fisher Scientific) were all used as received without any further purification. Solvents were purchased at the highest purity available from typical commercial sources and also used as received. Water was deionized with a Barnstead Nanopure Water System $(18.3 \mathrm{M} \Omega \bullet \mathrm{cm})$.

\subsection{Preparation of GQD-supported Cu nanoparticles}

The procedure for the preparation of GQDs has been detailed previously [37-39]. Note that low-frequency high-energy sonication is a powerful technology in surface cleaning as well as de-agglomeration and dispersion of bulk materials [40, 41]. Therefore, experimentally, concentrated $\mathrm{H}_{2} \mathrm{SO}_{4}$ and $\mathrm{HNO}_{3}$ were mixed with carbon fibers, and the mixture was subject to sonication for $2 \mathrm{~h}$ in order to separate those carbon fibers and then continuous stirring at $120{ }^{\circ} \mathrm{C}$ for $24 \mathrm{~h}$. The sonication was carried out with a VWR B1500A-MTH sonicator with a power of $143 \mathrm{~W}$ and a frequency of $40 \mathrm{kHZ}$. The mixture was then cooled down to room temperature and diluted with Nanopure water with the $\mathrm{pH}$ adjusted to 8 by $\mathrm{Na}_{2} \mathrm{CO}_{3}$. Then the solution was dialyzed in a dialysis bag, affording purified GQDs. 
The GQDs prepared above were then used for the preparation of Cu/GQD nanocomposites. In a typical reaction, a calculated amount of $\mathrm{CuSO}_{4}$ and $\mathrm{NaOAc}$ (at a 1:6 molar feed ratio) were dissolved in $50 \mathrm{~mL}$ of 1,2-propanediol together with a certain amount of the GQDs prepared above. The mixture was first subject to nitrogen bubbling for $30 \mathrm{~min}$ and then thermal refluxing at $140{ }^{\circ} \mathrm{C}$ under continuous stirring for $1 \mathrm{~h}$ before the solution was cooled down. The black precipitates were collected and purified with a copious amount of acetonitrile and Nanopure water. Four samples were prepared at varied $\mathrm{Cu} / \mathrm{C}$ atomic ratios $(x)$ and denoted as \#1 to \#4.

\subsection{Hydrothermal treatment of $\mathrm{Cu} / \mathrm{GQD}$ composites}

A calculated amount of the $\mathrm{Cu} / \mathrm{GQD}(x=2.88 \%)$ composites prepared above was dispersed in water in a Teflon-lined stainless autoclave, which was then placed in a Thermolyne Type F1500 muffle furnace. The hydrothermal treatment was carried out for $12 \mathrm{~h}$ at four different temperatures $\left(140{ }^{\circ} \mathrm{C}, 160{ }^{\circ} \mathrm{C}, 180{ }^{\circ} \mathrm{C}\right.$, and $\left.200^{\circ} \mathrm{C}\right)$.

\subsection{Characterization}

The morphology and size of the $\mathrm{Cu} / \mathrm{GQD}$ nanoparticles were characterized by transmission electron microscopic studies (TEM, Philips CM300 at 300kV). Raman spectroscopic measurements were carried out with a Delta NU 532 nm Raman spectrometer. Xray photoelectron spectra (XPS) were recorded with a PHI 5400/XPS instrument equipped with an $\mathrm{Al} \mathrm{K} \alpha$ source operated at $350 \mathrm{~W}$ and $10^{-9}$ Torr. Silicon wafers were sputtered by argon ions to remove carbon from the background and used as substrates. Deconvolution of the XPS spectra was carried out by using XPSPEAK 4.1 with a Shirley-type background.

\subsection{Electrochemistry}


Electrochemical tests were carried out in a standard three-electrode cell connected to a CHI 710C electrochemical workstation, with a Pt foil counter electrode and a reversible hydrogen reference electrode (RHE). The working electrode is a rotating platinum ring/glassycarbon disk electrode (RRDE). A calculated amount of the $\mathrm{Cu} / \mathrm{GQD}$ nanocomposites prepared above was dispersed in water to prepare a catalyst ink which was then slowly dropcast onto the glassy-carbon disk electrode surface of the RRDE and dried under gentle $\mathrm{N}_{2}$ in order to minimize the so-called "coffee ring" effects [42]. The catalyst films were then coated with $3 \mu \mathrm{L}$ of a dilute Nafion solution (0.1 wt.\%) and dried in air. The catalyst loadings were $15 \mu \mathrm{g}$ for all $\mathrm{Cu} / \mathrm{GQD}$ samples.

\section{Results and discussion}

The chemical compositions and valence states of the $\mathrm{Cu} / \mathrm{GQD}$ nanocomposites were first evaluated by XPS measurements. Figure 1 (A) depicts the survey spectra of the series of samples where the $\mathrm{C} 1 \mathrm{~s}$ electrons can be readily identified at ca. $284 \mathrm{eV}$, and the $\mathrm{O} 1 \mathrm{~s}$ and Auger peaks at $532 \mathrm{eV}$ and $980 \mathrm{eV}$ are also very prominent (the Si2p peaks are from the Si substrate) [43]. The $\mathrm{Cu} 2 \mathrm{p}$ electrons are expected to be found at around $934 \mathrm{eV}$. Yet the peak is visible only for the sample with the highest $\mathrm{Cu}$ loading (sample \#4) and becomes increasingly difficult to identify with decreasing copper concentration (\#1 - \#3). In high-resolution scans, however, both C1s and $\mathrm{Cu} 2 \mathrm{p}$ electrons can be easily resolved. For all samples, deconvolution of the $\mathrm{C} 1 \mathrm{~s}$ spectra in panel (B) yields three major components [44]. The first is $\mathrm{sp}^{2} \mathrm{C}$ (green curves) which exhibited a rather consistent binding energy among the samples within the narrow range of $284.7-285.0 \mathrm{eV}$. The second is carbon in $\mathrm{C}-\mathrm{OH}$ (yellow curves) with the peak binding energy between 285.5 and $286.2 \mathrm{eV}$. The third is $\mathrm{C}=\mathrm{O} / \mathrm{COOH}$ (blue curves) where the binding energy exhibited a rather apparent disparity among the samples, (\#1) $287.11 \mathrm{eV}$, (\#2) $289.06 \mathrm{eV}$, (\#3) $287.67 \mathrm{eV}$, and (\#4) 
$288.22 \mathrm{eV}$, likely due to a different combination of $\mathrm{C}=\mathrm{O}$ and $\mathrm{COOH}$ moieties. In addition, based on the integrated peak areas, the fraction of $\mathrm{C}=\mathrm{O} / \mathrm{COOH}$ carbons among the total carbons in each sample was estimated to be (\#2) $6.6 \%<(\# 4) 13.6 \%<(\# 3) 15.5 \%<(\# 1) 24.8 \%$. That is, sample \#2 exhibited the least amount of defective carbons in the series. Additionally, in samples (\#1), $(\# 3)$ and (\#4) the primary form was carbonyl carbon $(\mathrm{C}=\mathrm{O})$ whereas in sample (\#2), carboxylic carbon $(\mathrm{COOH})[44]$.

As for the $\mathrm{Cu} 2 \mathrm{p}$ electrons in panel $(\mathrm{C})$, three major peaks were identified by spectral deconvolution with the binding energies very consistent among the four samples. Of these, the peaks at ca. $934.5 \mathrm{eV}$ and $954.3 \mathrm{eV}$ are rather consistent with the $\mathrm{Cu} 2 \mathrm{p}_{3 / 2}$ and $\mathrm{Cu} 2 \mathrm{p}_{1 / 2}$ electrons of metallic copper, respectively [45]. Yet, as the binding energy of $\mathrm{Cu}(\mathrm{I})$ and $\mathrm{Cu}(0)$ is only $0.1 \mathrm{eV}$ apart, the presence of $\mathrm{Cu}(\mathrm{I})$ cannot be excluded [46]. In fact, from panel (A), one can see a broad peak at around $570 \mathrm{eV}$ that is consistent with the $\mathrm{LMM}-2$ auger transitions of $\mathrm{Cu}(\mathrm{I})$, indicating at least partial oxidation of the nanoparticles into $\mathrm{Cu}_{2} \mathrm{O}$ [45]. Additionally, the emergence of a satellite peak at ca. $944 \mathrm{eV}$ between the $\mathrm{Cu} 2 \mathrm{p}_{3 / 2}$ and $\mathrm{Cu} 2 \mathrm{p}_{1 / 2}$ peaks suggested the formation of $\mathrm{CuO}$. Such a satellite feature is typically observed in ions with a partially filled $3 \mathrm{~d}$ shell (e.g., $\mathrm{Cu}(\mathrm{II}))$ but absent in ions with a completely filled $3 \mathrm{~d}$ shell (e.g., $\mathrm{Cu}(\mathrm{I})$ and $\mathrm{Cu}(0)$ ), and has been largely ascribed to the shake-up effect where the outgoing electron interacts with a valence electron and excites it to a higher energy level [47]. Similar behaviors have been observed in previous studies with alkyne-capped copper nanoparticles [46]. Furthermore, based on the integrated peak areas, the fraction of $\mathrm{Cu}$ (II) among the copper species was all around $30 \%$, whereas the atomic ratio of $\mathrm{Cu} / \mathrm{C}$ in the nanocomposites was estimated to be approximately (\#1) 2.34\%, (\#2), 2.88\%, (\#3) $3.32 \%$ and (\#4) $3.54 \%$. 

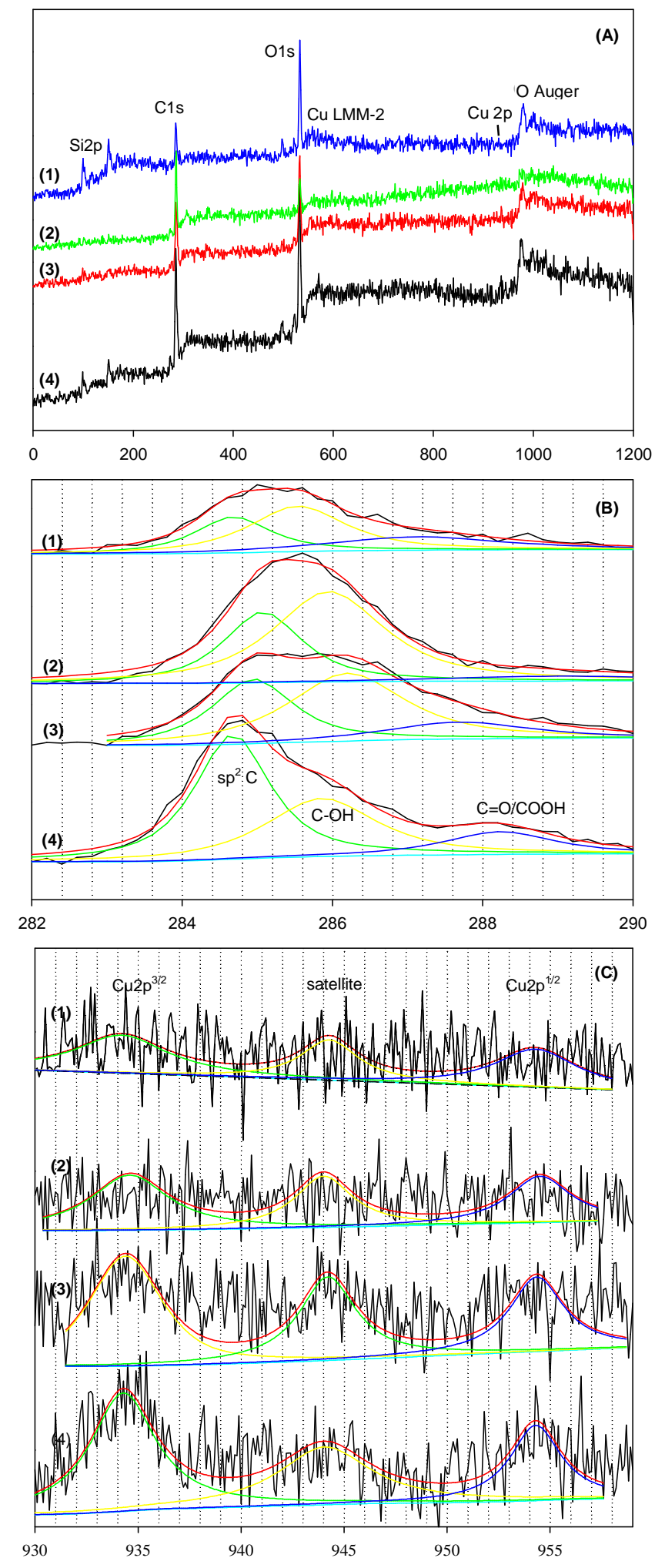

Binding Energy (eV)

Figure 1. (A) XPS survey spectra and high-resolution scans of (B) C1s and (C) Cu2p electrons of 
$\mathrm{Cu} / \mathrm{GQD}$ nanocomposites at different $\mathrm{Cu} / \mathrm{C}$ atomic ratios $(x)$. In panels $(\mathrm{B})$ and $(\mathrm{C})$, black curves are experimental data and colored curves are deconvolution fits.

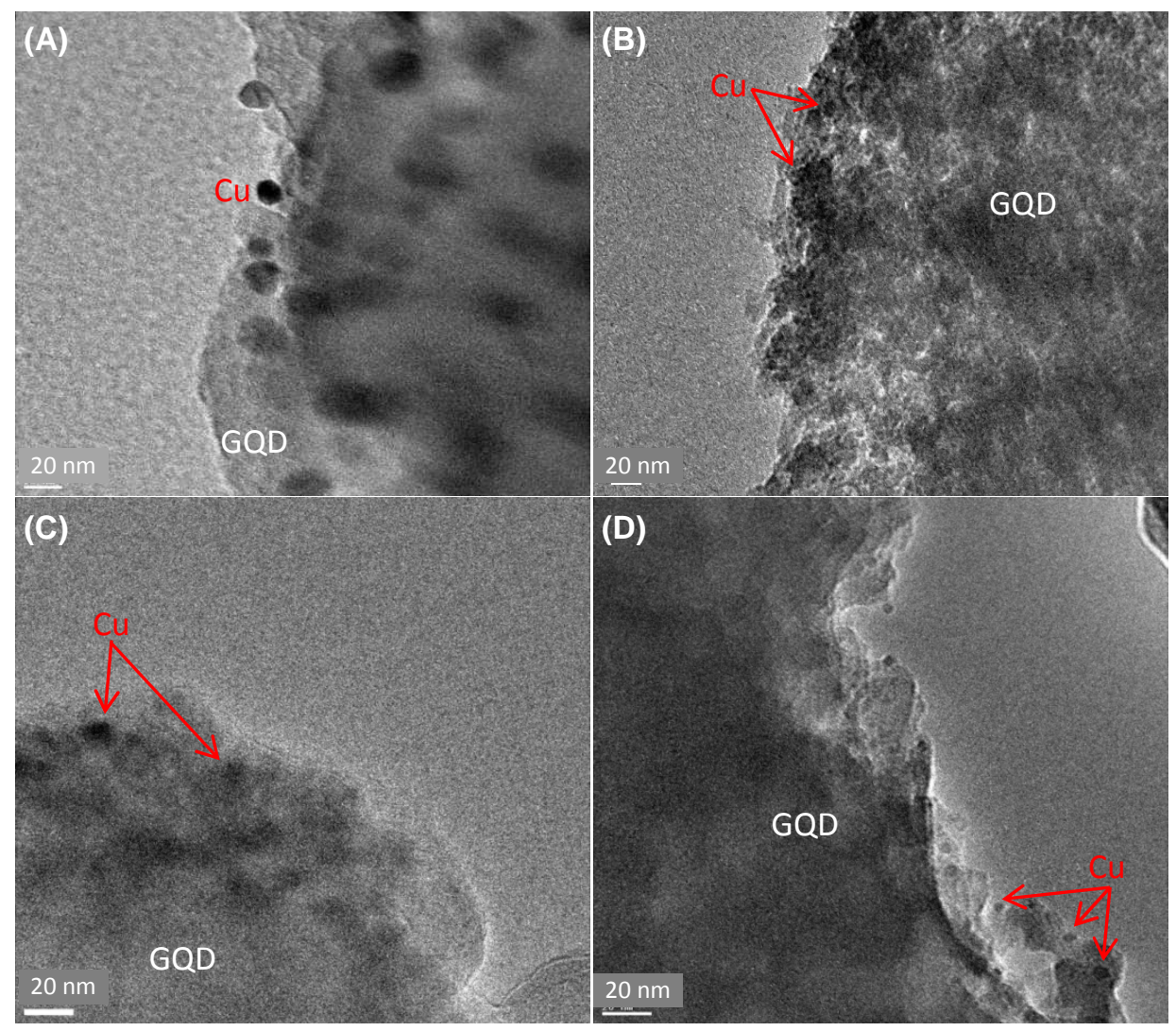

Figure 2. TEM micrographs of $\mathrm{Cu} / \mathrm{GQD}$ nanocomposites at different $\mathrm{Cu} / \mathrm{C}$ atomic ratios $(x):(\mathrm{A}) x=3.54 \%$, (B) $x=3.32 \%,(C) x=2.88 \%$, and (D) $x=2.34 \%$. Scale bars are all $20 \mathrm{~nm}$.

The structures of the Cu/GQD nanocomposites were then examined by TEM measurements. Figure 2 shows representative TEM micrographs of Cu/GQD $(x)$ nanocomposites at different $\mathrm{Cu} / \mathrm{C}$ atomic ratios: $(\mathrm{A}, \# 4) x=3.54 \%,(\mathrm{~B}, \# 3) x=3.32 \%,(\mathrm{C}, \# 2) x=2.88 \%$, and $(\mathrm{D}$, \#1) $x=2.34 \%$. The formation of copper nanoparticles was evidenced by the dark-contrast objects (signified by the red arrows), which were embedded within the low-contrast GQDs that showed various degrees of agglomeration in all four samples. Furthermore, one can see that the size of the copper nanoparticles varied rather drastically with the copper loading (Figure S1): ca. 15.1 
$\mathrm{nm}$ at $x_{\mathrm{Cu}}=3.54 \%$ in panel (A), $14.2 \mathrm{~nm}$ at $x_{\mathrm{Cu}}=3.32 \%$ in panel (B), $10.2 \mathrm{~nm}$ at $x_{\mathrm{Cu}}=2.88 \%$ in panel (C), and $5.5 \mathrm{~nm}$ at $x_{\mathrm{Cu}}=2.34 \%$ in panel (D). Such a variation of the nanoparticle dimensions might be accounted for by the nanoparticle growth dynamics where increasing concentration of capping ligands (i.e., GQDs) is known to lead to enhanced passivation of the nanoparticles and hence diminishing sizes [48].

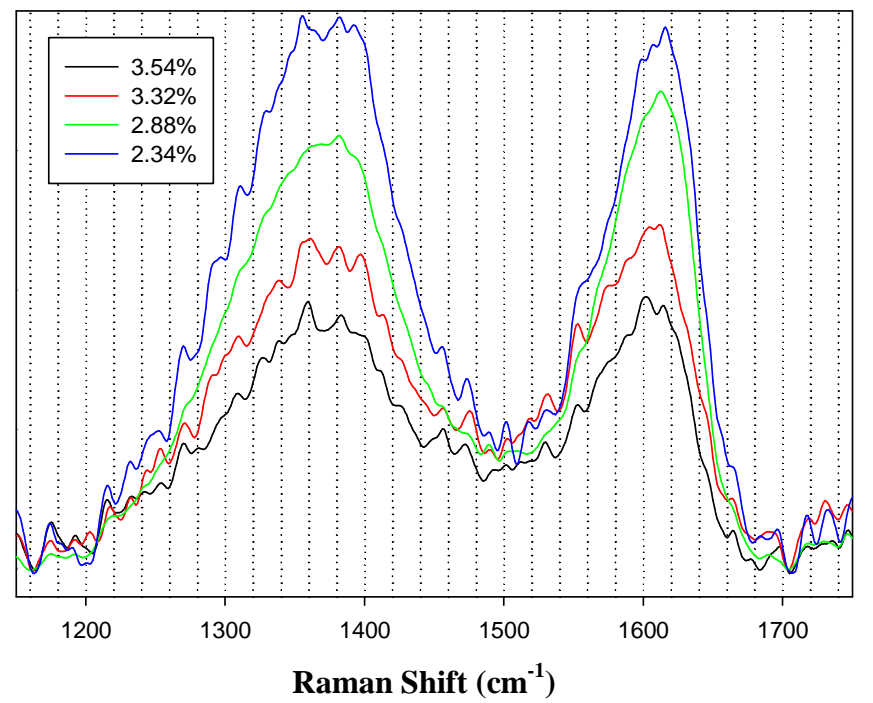

Figure 3. Raman spectra of $\mathrm{Cu} / \mathrm{GQD}$ nanocomposites at different $\mathrm{Cu} / \mathrm{C}$ atomic ratios $(x)$ which are specified in figure legends.

Further structural insights were unraveled by Raman spectroscopic measurements. From Figure 3, one can see two prominent vibrational bands at $c a .1370 \mathrm{~cm}^{-1}$ and $1615 \mathrm{~cm}^{-1}$ for all samples, which might be assigned to the D and G bands of GQDs, respectively. Additionally, the ratio of the $\mathrm{D}$ and $\mathrm{G}$ band intensity $\left(\mathrm{I}_{\mathrm{D}} / \mathrm{I}_{\mathrm{G}}\right)$ increases in the order of $0.91(\# 2, x=2.88 \%)<0.96$ $(\# 3, x=3.32 \%)<0.97(\# 4, x=3.54 \%)<0.98(\# 1, x=2.34 \%)$, suggesting that the Cu/GQD (2.88\%) sample exhibited the least amount of structural defects among the series. This is consistent with results from the XPS measurements (Figure 1). Such a correlation between the XPS and Raman characterizations of GQD structural defects has also been observed previously with Pt/GQD nanocomposites [37]. 


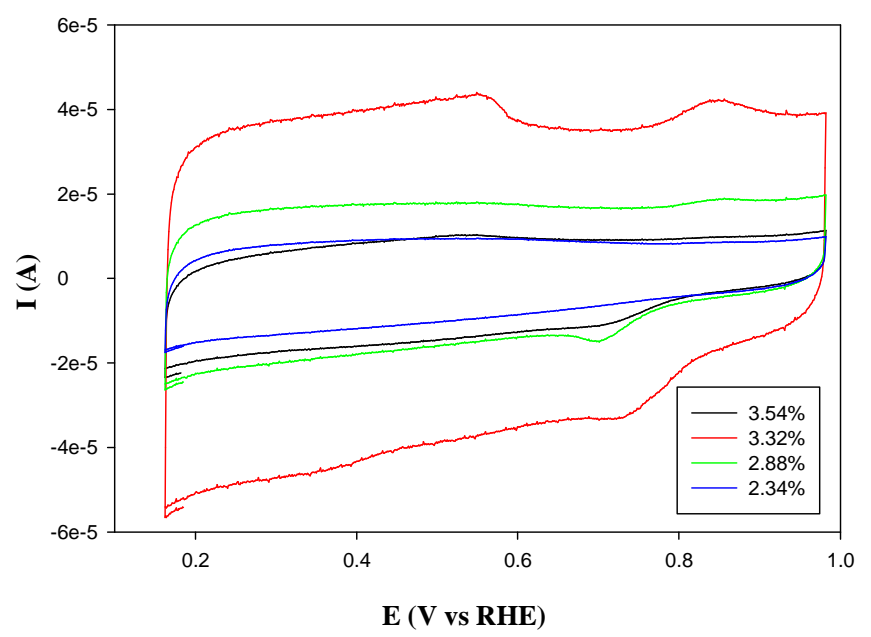

Fig.4. Cyclic voltammograms of a glassy-carbon electrode (dia. $5.61 \mathrm{~mm}$ ) modified with $\mathrm{Cu} / \mathrm{GQD}$ nanocomposites in a nitrogen-purged $0.1 \mathrm{M} \mathrm{NaOH}$ solution. Potential scan rate $10 \mathrm{mV} / \mathrm{s}$. Catalyst loading $15 \mu \mathrm{g}$.

The electrocatalytic activity of the nanocomposite catalysts for ORR was then tested by voltammetric measurements. Figure 4 shows the cyclic voltammograms of a glassy-carbon electrode modified with $15 \mu \mathrm{g}$ of $\mathrm{Cu} / \mathrm{GQDs}$ in a nitrogen-purged $\mathrm{NaOH}$ solution. It can be seen that the Cu/GQD (3.32\%, red curve) sample exhibited two rather prominent anodic peaks at around $+0.55 \mathrm{~V}$ and $+0.84 \mathrm{~V}$ (vs RHE), where the former might be ascribed to the formation of a monolayer of $\mathrm{Cu}_{2} \mathrm{O}$ while the latter to the formation of a thick multilayer film of $\mathrm{CuO}$, and a cathodic peak at around $+0.70 \mathrm{~V}$ that is likely to originate from the partial reduction of $\mathrm{CuO}$ to $\mathrm{Cu}_{2} \mathrm{O}[46,49,50]$. Similar voltammetric features can be seen with other $\mathrm{Cu} / \mathrm{GQD}$ (2.88\%, green curve; $3.54 \%$, black curve) samples. In contrast, for the Cu/GQD (2.34\%, blue curve), the voltammogram was largely featureless, possibly because of the encapsulation of the copper nanoparticles by the GQDs (Figure 2). Such encapsulation effects may also account for the apparent variation of the double-layer charging currents and hence the effective electrochemical surface area among the series, which increased in the order of Cu/GQD $(\# 1,2.34 \%)<(\# 4$, $3.54 \%)<(\# 2,2.88 \%)<(\# 3,3.32 \%)$, despite the same catalyst loading. 
Figure 5 shows the RRDE voltammagrams of the same electrodes in an oxygen-saturated $0.1 \mathrm{M} \mathrm{NaOH}$ solution at the rotation rates of 100 to $2500 \mathrm{rpm}$. We can see that for all $\mathrm{Cu} / \mathrm{GQD}$ nanocomposites, non-zero cathodic currents started to emerge at electrode potentials more negative than $+0.80 \mathrm{~V}$, and reached a plateau at sufficiently negative potentials (e.g., $\mathrm{E}<+0.60$ V), indicating apparent ORR activity. Yet, marked discrepancy can be seen of the electrocatalytic performance. For instance, the onset potential varied with the copper concentration in the nanocomposites, $(\# 2, x=2.88 \%)+0.82 \mathrm{~V} \approx(\# 3, x=3.32 \%)+0.82 \mathrm{~V}>(\# 4$, $x=3.54 \%)+0.81 \mathrm{~V}>(\# 1, x=2.34 \%)+0.75 \mathrm{~V}$. A similar variation can be seen with the disk limiting current density $\left(\mathrm{J}_{\mathrm{lim}}\right)$ at $+0.40 \mathrm{~V}$ at the rotation rate of $1600 \mathrm{rpm},(\# 2, x=2.88 \%) 40.5$ $\mathrm{A} / \mathrm{m}^{2}>(\# 3, x=3.32 \%) 39.7 \mathrm{~A} / \mathrm{m}^{2}>(\# 1, x=2.34 \%) 32.4 \mathrm{~A} / \mathrm{m}^{2}>(\# 4, x=3.54 \%) 29.6 \mathrm{~A} / \mathrm{m}^{2}$.

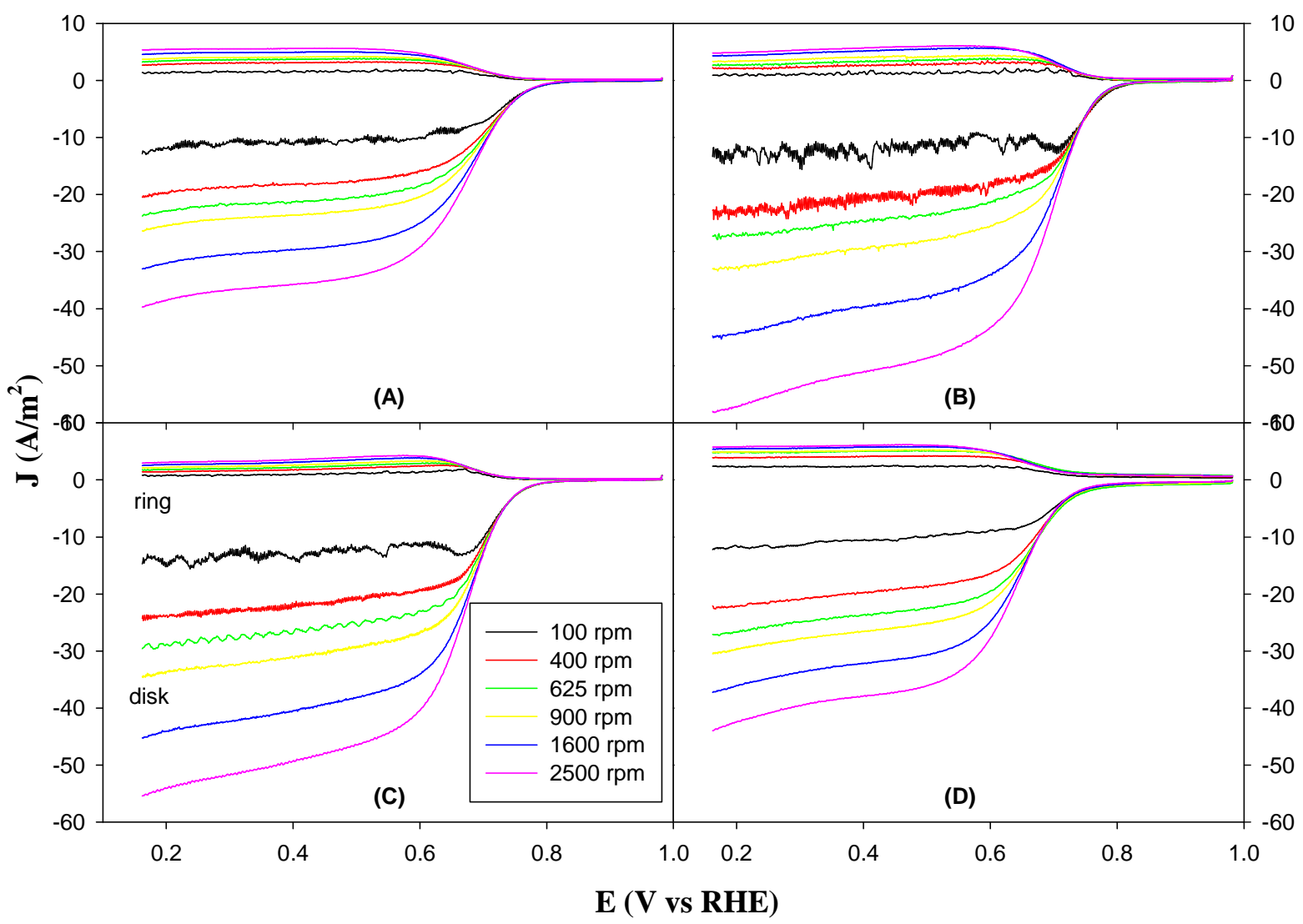


Figure 5. RRDE voltammograms of a platinum ring-glassy carbon disk electrode with the disk electrode modified with $15 \mu \mathrm{g}$ of $(\mathrm{A}) \mathrm{Cu} / \mathrm{GQD}$ at different $\mathrm{Cu} / \mathrm{C}$ atomic ratios $(x),(\mathrm{A}) 3.54 \%$, (B) $3.32 \%$, (C) $2.88 \%$, and (D) $2.34 \%$ in an oxygen-saturated $0.1 \mathrm{M} \mathrm{NaOH}$ solution. Current density was obtained by normalizing the voltammetric currents to the electrode geometrical surface area $\left(0.247 \mathrm{~cm}^{2}\right)$. Electrode rotation rates are specified in the figure legends. Ring potential was set at $+1.30 \mathrm{~V}$ vs RHE.

Furthermore, one can see that at the ring potential of $+1.30 \mathrm{~V}$, the ring currents were at least one order of magnitude smaller than the disk currents for all four nanocomposites catalysts. Based on the corresponding ring $\left(\mathrm{I}_{\text {Ring }}\right)$ and disk currents $\left(\mathrm{I}_{\text {Disk }}\right)$, the number $(\mathrm{n})$ of electron transfer involved in ORR can be quantitatively estimated by $\mathrm{n}=4 \mathrm{I}_{\text {Disk }} /\left(\mathrm{I}_{\text {Disk }}+\mathrm{I}_{\text {Ring }} / \mathrm{N}\right)$ with $\mathrm{N}$ being the collection efficiency (37\%) [51]. Figure 6 shows the variation of $n$ with electrode potential. It can be seen that the $\mathrm{n}$ values increased rapidly with the electrode potential swept from ca. $+0.80 \mathrm{~V}$ to $+0.75 \mathrm{~V}$ in the so-called kinetic-controlled region, and at more negative potentials, the increment remained apparent but slow. Within the potential range of +0.60 to $+0.10 \mathrm{~V}$, the $\mathrm{n}$ values also exhibited a variation with the copper concentration $(x)$ in the $\mathrm{Cu} / \mathrm{GQD}$ composites, $(\# 4,3.54 \%)<(\# 3,3.32 \%) \approx(\# 1,2.34 \%)<(\# 2,2.88 \%)$. For instance, at $+0.40 \mathrm{~V}, \mathrm{n}$ $=2.76$ for $x=3.54 \%, 3.17$ for $x=3.32 \%, 3.20$ for $x=2.34 \%$, and 3.42 for $x=2.88 \%$, corresponding to the fraction of peroxide species in the final products of $62 \%, 41 \%, 40 \%$, and $29 \%$, respectively. This signifies that ORR took place predominantly by the two-electron pathway at $\mathrm{Cu} / \mathrm{GQD}(\# 4,3.54 \%)$ whereas four-electron reduction to hydroxide $\left(\mathrm{OH}^{-}\right)$was the primary process at other nanocomposites catalysts, in particular, sample \#2 which displayed a highest $\mathrm{n}$ value and lowest peroxide yield. 


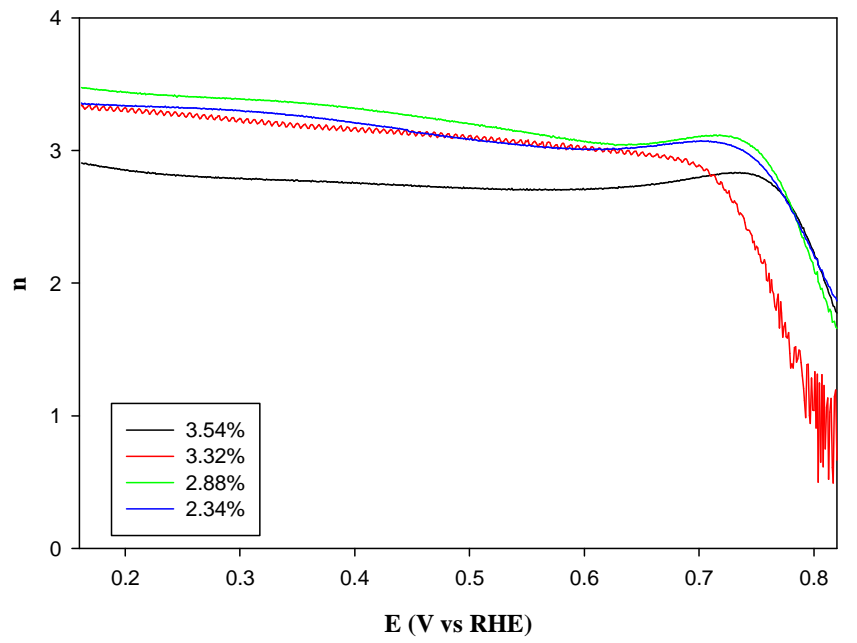

Figure 6. The number of electron transfer $(\mathrm{n})$ in oxygen reduction catalyzed by $\mathrm{Cu} / \mathrm{GQD}$ at different $\mathrm{Cu} / \mathrm{C}$ atomic ratios $(x)$ which were specified in the figure legends. Data were calculated from the RRDE voltammograms at 1600 rpm in Figure 5.

Taken together, these results indicate that the $\mathrm{Cu} / \mathrm{GQD}$ nanocomposites with a $\mathrm{Cu} / \mathrm{C}$ atomic ratio of $2.88 \%$ stood out as the best among the series within the context of limiting currents, onset potential, and number of electron transfer. Importantly, the performance might be further enhanced by hydrothermal treatment of the samples at controlled temperatures. Figure 7 depicts the RDE voltammograms of Cu/GQD-2.88\% after hydrothermal treatments at controlled temperatures: (A) $140{ }^{\circ} \mathrm{C}$, (B) $160{ }^{\circ} \mathrm{C}$, (C) $180{ }^{\circ} \mathrm{C}$ and (D) $200{ }^{\circ} \mathrm{C}$ in oxygen-saturated $0.1 \mathrm{M}$ $\mathrm{NaOH}$. In comparison to the results of the as-prepared Cu-GQD-2.88\% sample, one can see that the ORR activity of the $\mathrm{Cu} / \mathrm{GQD}-2.88 \%$ nanocomposites treated at $140{ }^{\circ} \mathrm{C}, 180{ }^{\circ} \mathrm{C}$ and $200{ }^{\circ} \mathrm{C}$ was almost unchanged; yet, significance improvement can be seen with the sample treated at 160 ${ }^{\circ} \mathrm{C}$, as manifested by a $30 \mathrm{mV}$ positive shift of the onset potential and an appreciably higher limiting current. For instance, at $+0.40 \mathrm{~V}$, the limiting current density at $1600 \mathrm{rpm}$ remained at ca. $40.5 \mathrm{~A} / \mathrm{m}^{2}$ for the as-prepared $\mathrm{Cu} / \mathrm{GQD}-2 / 88 \%$ sample and after hydrothermal treatment at 140 ${ }^{\circ} \mathrm{C}, 180{ }^{\circ} \mathrm{C}$ and $200{ }^{\circ} \mathrm{C}$; yet it increased markedly by about $40 \%$ to $56.7 \mathrm{~A} / \mathrm{m}^{2}$ for the sample treated at $160{ }^{\circ} \mathrm{C}$. 
In addition, the number of electron transfer in ORR also shows a similar variation (determined from the corresponding RRDE voltammograms, Figure S2). From the figure inset, one can see that within the potential range of +1.0 to $+0.2 \mathrm{~V}$, the $\mathrm{n}$ values of the $160{ }^{\circ} \mathrm{C}$ sample were markedly higher than those of other samples which were almost identical. For instance, the $\mathrm{n}$ value at $+0.40 \mathrm{~V}$ increased from 3.42 to 3.64 after hydrothermal treatment at $160{ }^{\circ} \mathrm{C}$, indicating an increasingly dominant $4 \mathrm{e}$ reduction pathway for ORR.

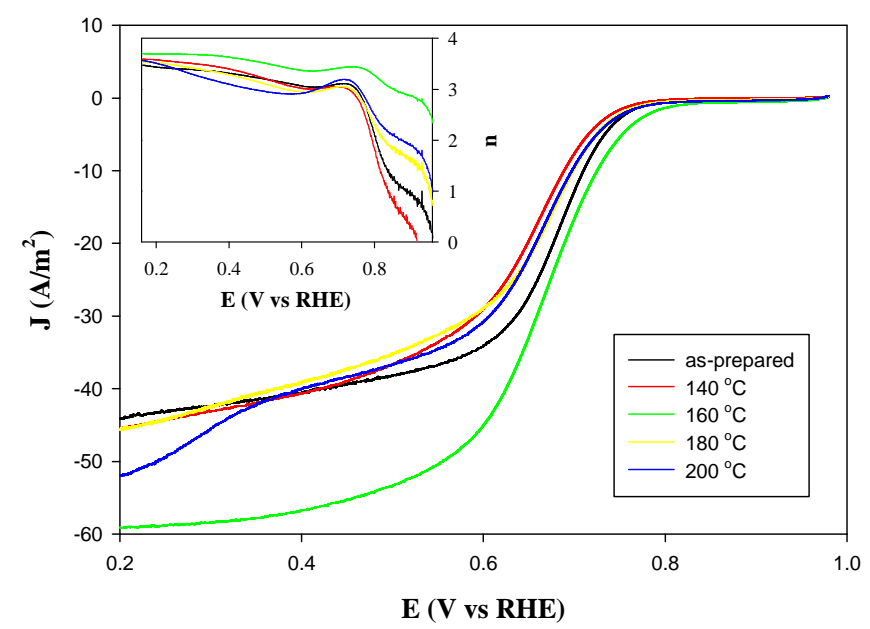

Figure 7. RRDE voltammograms of a glassy-carbon rotating disk electrode modified with $15 \mu \mathrm{g}$ of $\mathrm{Cu}$ GQD-2.88\% before and after hydrothermal treatment at different temperatures (specified in figure legends) in an oxygen-saturated $0.1 \mathrm{M} \mathrm{NaOH}$ solution. Current density was obtained by normalizing the voltammetric currents to the electrode geometrical surface area $\left(0.247 \mathrm{~cm}^{2}\right)$. Electrode rotation rate 1600 RPM. Inset shows the number of electron transfer $(n)$ in oxygen reduction at different electrode potentials Data were calculated from the RRDE voltammograms in Figure S2.

It should be noted that whereas the electrocatalytic performance of the $\mathrm{Cu} / \mathrm{GQD}$ nanocomposites remains subpar as compared to those of the Pt/GQD counterparts or commercial $\mathrm{Pt} / \mathrm{C}$ catalysts (Table 1 ) which typically exhibit an onset potential around $+1.0 \mathrm{~V}$ and $\mathrm{n} \approx 4.0[37$, 52], the activity is actually better than those of $\mathrm{Cu}_{2} \mathrm{O} / \mathrm{RGO}$ composites (onset potential $\sim+0.80 \mathrm{~V}$ and $\mathrm{n}$ in range of 3.2-3.6) [53] and alkyne-capped copper nanoparticles supported on carbon black $(n=2.5-2.7$ in the potential range of $+0.70 \mathrm{~V}$ to $+0.40 \mathrm{~V})$ [46]. Furthermore, the 
$\mathrm{Cu} / \mathrm{GQD}$ nanocomposites all exhibit far better catalytic activities than bulk polycrystalline $\mathrm{Cu}$ or CuNi electrode (onset potential $+0.36 \mathrm{~V}$ vs RHE in a borax buffer solution) $[54,55]$ and single crystalline $\mathrm{Cu}(100)$ or $\mathrm{Cu}(111)$ electrodes ( $\sim 0 \mathrm{~V}$ vs $\mathrm{RHE}$ in $\mathrm{H}_{2} \mathrm{SO}_{4}$ solution) $[56,57]$.

This apparent ORR performance might be ascribed to the intimate interactions between the copper nanoparticles and the GQD substrates where the GQD structural defects are known to manipulate the electronic interactions of the metal nanoparticles with oxygen species and hence the ORR activity [58]. It has been long known that there is a volcano-shaped relationship between the ORR activity and the d-band center of transition metals where Pt lies nearest the top of the volcano $[17,59,60]$. To reach the peak performance, it has been argued that the d-band center of Pt needs to be downshifted by $0.1-0.2 \mathrm{eV}$ so as to weaken the interactions with oxygen intermediates [61]. In fact, in a prior study [37], we observed that the ORR activity of Pt/GQD nanocomposites reached the maximum with about $20 \%$ structural defects of the GQDs. As copper exhibits even stronger affinity to oxygen than Pt and its d-band center lies on the right side of Pt [62], the copper d-band center has to be downshifted even more. This means that a substantially higher defect concentration is needed to enhance the ORR activity of $\mathrm{Cu} / \mathrm{GQD}$ nanocomposites. In fact, within the present experimental context, XPS measurements (Figure S3) showed that the optimal GQD defect concentration, corresponding to the Cu/GQD-2.88\% (160 $\left.{ }^{\circ} \mathrm{C}\right)$ sample which exhibited the best ORR activity among the series, was about three times higher at $63 \%$. Consistent results were obtained in Raman spectroscopic measurements (Figure S4).

Table 1. Summary of ORR activity of $\mathrm{Cu} / \mathrm{GQD}, \mathrm{Pt} / \mathrm{GQD}$, and $\mathrm{Pt} / \mathrm{C}$ nanocomposite catalysts.

\begin{tabular}{|c|c|c|c|}
\hline Catalysts & $\mathrm{E}_{\text {onset }}(\mathrm{V})$ & $\mathbf{n} \mathbf{( + \mathbf { 0 . 4 } \mathbf { V } \text { vs RHE) }}$ & $\begin{array}{c}\mathbf{J}_{\text {lim }}\left(\mathbf{A} / \mathbf{m}^{2}, \text { at } \mathbf{1 6 0 0} \mathbf{~ r p m} \text { and }\right. \\
\mathbf{+ 0 . 4 0} \mathbf{~ v s ~} \mathbf{R H E})\end{array}$ \\
\hline $\mathrm{Cu} / \mathrm{GQD}-3.54 \%$ & 0.81 & 2.76 & 29.6 \\
\hline
\end{tabular}




\begin{tabular}{|c|c|c|c|}
\hline $\mathrm{Cu} / \mathrm{GQD}-3.32 \%$ & 0.82 & 3.17 & 39.7 \\
\hline $\mathrm{Cu} / \mathrm{GQD}-2.88 \%$ & 0.82 & 3.42 & 40.5 \\
\hline $\mathrm{Cu} / \mathrm{GQD}-2.34 \%$ & 0.75 & 3.20 & 32.4 \\
\hline $\mathrm{Cu} / \mathrm{GQD}-2.88 \%-160^{\circ} \mathrm{C}$ & 0.85 & 3.64 & 56.7 \\
\hline $\mathrm{Pt} / \mathrm{C}[63]$ & 0.98 & $\sim 4.0$ & 51.8 \\
\hline $\mathrm{Pt} / \mathrm{GQD}[52]$ & 1.05 & $\sim 4.0$ & 58.7 \\
\hline
\end{tabular}

\section{Conclusions}

$\mathrm{Cu} / \mathrm{GQD}$ nanocomposites were readily prepared by thermolytic reduction of metal salts in the presence of GQDs in 1,2-propanediol. TEM measurements showed that the average diameter of the copper particles ranged from ca. 5 to $15 \mathrm{~nm}$, increasing with increasing $\mathrm{Cu} / \mathrm{C}$ atomic ratios which were quantitatively determined by XPS measurements. Electrochemical measurements showed that the sample with a $\mathrm{Cu} / \mathrm{C}$ atomic ratio of $2.88 \%$ exhibited the best $\mathrm{ORR}$ activity among the series within the context of onset potential, number of electron transfer, and limiting currents. The electrocatalytic performance might be further enhanced by hydrothermal treatment of the $\mathrm{Cu} / \mathrm{GQD}$ composite catalysts and $160{ }^{\circ} \mathrm{C}$ was identified as the optimal temperature where the corresponding sample exhibited the largest improvement of the ORR activity. This was ascribed to the manipulation of the electron density of the copper nanoparticles and hence the interactions with oxygen species by the GQD structural defects. In comparison to the Pt/GQD counterparts, the optimal concentration of the GQD structural defects were almost three times higher, consistent with the greater oxygen affinity of copper to oxygen as manifested in the volcano plot. The results further confirm the significance of metal-support interactions in the manipulation of nanoparticle electrocatalytic activity and might be exploited for the rational design and engineering of effective catalysts for fuel cell electrochemistry. 
Acknowledgments This work was supported in part by the National Science Foundation (CHE1265635 and DMR-1409396). TEM and XPS work was carried out at the National Center for Electron Microscopy and Molecular Foundry at the Lawrence Berkeley National Laboratory, respectively, as part of a user project.

\section{References}

[1] Song C, Zhang J. PEM Fuel Cell Electrocatalysis and Catalyst Layers: Fundamentals and Applications2008.

[2] Rabis A, Rodriguez P, Schmidt TJ. Electrocatalysis for Polymer Electrolyte Fuel Cells: Recent Achievements and Future Challenges. Acs Catal. 2012;2:864-90.

[3] Norskov JK, Rossmeisl J, Logadottir A, Lindqvist L, Kitchin JR, Bligaard T, et al. Origin of the Overpotential for Oxygen Reduction at a Fuel-Cell Cathode. J Phys Chem B. 2004;108:17886-92.

[4] M. Peuckert TY, R. A. Dalla Betta, and M. Boudart. Oxygen Reduction on Small Supported Platinum Particles. J Electrochem Soc. 1986;133:944-7.

[5] Mohamed S. El- Deab TO. An extraordinary electrocatalytic reduction of oxygen on gold nanoparticles-electrodeposited gold electrodes. Electrochem Commun. 2002;4:288-92.

[6] Demarconnay L, Coutanceau C, Léger JM. Electroreduction of dioxygen (ORR) in alkaline medium on $\mathrm{Ag} / \mathrm{C}$ and $\mathrm{Pt} / \mathrm{C}$ nanostructured catalysts-effect of the presence of methanol. Electrochim Acta. 2004;49:4513-21.

[7] Solorza-Feria O, Duron S. Temperature effects for oxygen reduction on Ru-nanoparticles in acid solution. Int J Hydrogen Energy2002. p. 451-5.

[8] U.A. Paulus AW, G.G. Scherer, T.J. Schmidt, V. Stamenkovic, N.M. Markovic, P.N. Ross. Oxygen reduction on high surface area Pt-based alloy catalysts in comparison to well defined smooth bulk alloy electrodes. Electrochim Acta. 2002;47:3787-98.

[9] H. Schulenburg EMI, G. Khelashvili, Roser,Bo"nnemann, A. Wokaun, and G. G. Scherer. Heat-Treated PtCo3 Nanoparticles as Oxygen Reduction Catalysts. J Phys Chem C. 2009;113:4069-77.

[10] Vinayan BP, Jafri RI, Nagar R, Rajalakshmi N, Sethupathi K, Ramaprabhu S. Catalytic activity of platinum-cobalt alloy nanoparticles decorated functionalized multiwalled carbon nanotubes for oxygen reduction reaction in PEMFC. Int J Hydrogen Energy. 2012;37:412-21.

[11] Wu Z-S, Yang S, Sun Y, Parvez K, Feng X, Müllen K. 3D Nitrogen-Doped Graphene Aerogel-Supported Fe3O4Nanoparticles as Efficient Electrocatalysts for the Oxygen Reduction Reaction. J Am Chem Soc. 2012;134:9082-5.

[12] Y Liang YL, H Wang, J Zhou, J Wang, T Regier, H Dai. Co3O4 nanocrystals on graphene as a synergistic catalyst for oxygen reduction reaction. Nat Mater. 2011;10:780-6.

[13] Wang K, Wang RF, Li H, Wang H, Mao XF, Linkov V, et al. N-doped carbon encapsulated Co3O4 nanoparticles as a synergistic catalyst for oxygen reduction reaction in acidic media. Int J Hydrogen Energy. 2015;40:3875-82.

[14] Song TS, Wang DB, Wang HQ, Li XX, Liang YY, Xie JJ. Cobalt oxide/nanocarbon hybrid materials as alternative cathode catalyst for oxygen reduction in microbial fuel cell. Int J Hydrogen Energy. 2015;40:3868-74.

[15] He XB, Yin FX, Li GR. A Co/metal-organic-framework bifunctional electrocatalyst: The effect of the surface cobalt oxidation state on oxygen evolution/reduction reactions in an alkaline electrolyte. Int J Hydrogen Energy. 2015;40:9713-22. 
[16] Alonso-Vante N. Chaper 14 Transition Metal Chalcogenides for Oxygen Reduction. Electrocatalysis in Fuel Cells: Springer-Verlag London; 2013.

[17] Zhang J, Vukmirovic MB, Xu Y, Mavrikakis M, Adzic RR. Controlling the Catalytic Activity of PlatinumMonolayer Electrocatalysts for Oxygen Reduction with Different Substrates. Angew Chem Int Ed. 2005;44:2132-5.

[18] Elezovic NR, Babic BM, Radmilovic VR, Vracar LM, Krstajic NV. Synthesis and characterization of $\mathrm{MoOx}-\mathrm{Pt} / \mathrm{C}$ and TiOx-Pt/C nano-catalysts for oxygen reduction. Electrochim Acta. 2009;54:2404-9.

[19] Sebastian D, Lazaro MJ, Suelves I, Moliner R, Baglio V, Stassi A, et al. The influence of carbon nanofiber support properties on the oxygen reduction behavior in proton conducting electrolytebased direct methanol fuel cells. Int J Hydrogen Energy. 2012;37:6253-60.

[20] Park S, Shao Y, Kou R, Viswanathan VV, Towne SA, Rieke PC, et al. Polarization Losses under Accelerated Stress Test Using Multiwalled Carbon Nanotube Supported Pt Catalyst in PEM Fuel Cells. J Electrochem Soc. 2011;158:B297.

[21] Li Y, Li Y, Zhu E, McLouth T, Chiu C-Y, Huang X, et al. Stabilization of High-Performance Oxygen Reduction Reaction Pt Electrocatalyst Supported on Reduced Graphene Oxide/Carbon Black Composite. J Am Chem Soc. 2012;134:12326-9.

[22] Seo MH, Choi SM, Kim HJ, Kim WB. The graphene-supported Pd and Pt catalysts for highly active oxygen reduction reaction in an alkaline condition. Electrochem Commun. 2011;13:182-5.

[23] K. Zhang QY, G. Chen , Y. Zhai, L. Wang , H. Wang , J. Zhao , J. Liu , J. Jia , and H. Li. Effects of Acid Treatment of Pt-Ni Alloy Nanoparticles@Graphene on the Kinetics of the Oxygen Reduction Reaction in Acidic and Alkaline Solutions. J Phys Chem C. 2011;115:379-89.

[24] Jin NA, Han JY, Wang H, Zhu XL, Ge QF. A DFT study of oxygen reduction reaction mechanism over O-doped graphene-supported Pt-4, Pt3Fe and Pt3V alloy catalysts. Int J Hydrogen Energy. 2015;40:5126-34.

[25] Sharma S, Pollet BG. Support materials for PEMFC and DMFC electrocatalysts-A review. J Power Sources. 2012;208:96-119.

[26] Xing Y. Synthesis and Electrochemical Characterization of Uniformly-Dispersed High Loading Pt Nanoparticles on Sonochemically-Treated Carbon Nanotubes. J Phys Chem B. 2004;108:19255-9.

[27] Hu PG, Liu K, Deming CP, Chen SW. Multifunctional Graphene-Based Nanostructures for Efficient Electrocatalytic Reduction of Oxygen. J Chem Technol Biotechnol. 2015:accepted.

[28] Debe MK. Electrocatalyst approaches and challenges for automotive fuel cells. Nature. 2012;486:43-51.

[29] Ohno S-y, Yagyuu K, Nakatsuji K, Komori F. Dissociation preference of oxygen molecules on an inhomogeneously strained Cu(001) surface. Surf Sci. 2004;554:183-92.

[30] Küppers TKaJ. The Kinetics of the Reaction of Gaseous Hydrogen Atoms with Oxygen on Cu(111) Surfaces toward Water. J Phys Chem B. 2001;105:8369-74.

[31] D. Kolovos-Vellianitis TK, J. Küppers. Interaction of gaseous hydrogen atoms with oxygen cover $\mathrm{Cu}(100)$ surfaces. Surf Sci. 2001;482-485:166-70.

[32] M.V. Vazquez SRdS, E.J. Calvo, D.J. Schiffrin. The electrochemical reduction of hydrogen peroxide on polycrystalline copper in borax buffer. J Electroanal Chem. 1994;374:189-97.

[33] S. Cere MV, S.R. de Sanchez, D.J. Schiffrin. Surface redox catalysis and reduction kinetics of oxygen on copper-nickel alloys. J Electroanal Chem. 2001;505:118-24.

[34] Jiang T, Brisard GM. Determination of the kinetic parameters of oxygen reduction on copper using a rotating ring single crystal disk assembly (RRDCu(hkl)E). Electrochim Acta. 2007;52:4487-96.

[35] Yan X-Y, Tong X-L, Zhang Y-F, Han X-D, Wang Y-Y, Jin G-Q, et al. Cuprous oxide nanoparticles dispersed on reduced graphene oxide as an efficient electrocatalyst for oxygen reduction reaction. Chem Commun. 2012;48:1892. 
[36] Samulski YSaE. Exfoliated Graphene Separated by Platinum Nanoparticles. Chem Mater. 2008;20:6792-7.

[37] Song Y, Chen SW. Graphene Quantum-Dot-Supported Platinum Nanoparticles: Defect-Mediated Electrocatalytic Activity in Oxygen Reduction. Acs Appl Mater Interfaces. 2014;6:14050-60.

[38] He G, Song Y, Liu K, Walter A, Chen S, Chen S. Oxygen Reduction Catalyzed by Platinum Nanoparticles Supported on Graphene Quantum Dots. ACS Catal. 2013;3:831-8.

[39] Peng J, Gao W, Gupta BK, Liu Z, Romero-Aburto R, Ge LH, et al. Graphene Quantum Dots Derived from Carbon Fibers. Nano Lett. 2012;12:844-9.

[40] Pollet BG. Electrocatalysis. 2014;5:330-43.

[41] Pollet BG, Goh JTE. The importance of ultrasonic parameters in the preparation of fuel cell catalyst inks. Electrochim Acta. 2014;128:292-303.

[42] K. Shinozaki JWZ, S. Pylypenko, B. S. Pivovar, S. S. Kocha. J Electrochem Soc. 2015;162:F1384-F96.

[43] Aoki T, Kondo H, Matsunari S. Apparatus for contamination control development in EUVA. P Soc Photo-Opt Ins. 2005;5751:1137-46.

[44] Rao CNR, Sood AK. Graphene : synthesis, properties, and phenomena. Weinheim: Wiley-VCH; 2013.

[45] Ghodselahi T, Vesaghi MA, Shafiekhani A, Baghizadeh A, Lameii M. XPS study of the Cu@Cu2O coreshell nanoparticles. Appl Surf Sci. 2008;255:2730-4.

[46] Liu K, Song Y, Chen SW. Electrocatalytic activities of alkyne-functionalized copper nanoparticles in oxygen reduction in alkaline media. J Power Sources. 2014;268:469-75.

[47] Kim KS. Charge transfer transition accompanying $x$-ray photoionization in transition-metal compounds. J Elec Spec Rel Phen. 1974;3:217-26.

[48] Chen SW, Templeton AC, Murray RW. Monolayer-protected cluster growth dynamics. Langmuir. 2000;16:3543-8.

[49] Elhaleem SMA, Ateya BG. Cyclic Voltammetry of Copper in Sodium-Hydroxide Solutions. J Electroanal Chem. 1981;117:309-19.

[50] S.M.ABD EL HALEEM BGA. Cyclic voltammetry of copper in sodium hydroxide solutions. J Electroanal Chem. 1981;117:309-19.

[51] Zhou ZY, Kang XW, Song Y, Chen SW. Enhancement of the electrocatalytic activity of Pt nanoparticles in oxygen reduction by chlorophenyl functionalization. Chem Commun. 2012;48:3391-3.

[52] He GQ, Song Y, Liu K, Walter A, Chen S, Chen SW. Oxygen Reduction Catalyzed by Platinum Nanoparticles Supported on Graphene Quantum Dots. Acs Catal. 2013;3:831-8.

[53] Yan XY, Tong XL, Zhang YF, Han XD, Wang YY, Jin GQ, et al. Cuprous oxide nanoparticles dispersed on reduced graphene oxide as an efficient electrocatalyst for oxygen reduction reaction. Chem Commun. 2012;48:1892-4.

[54] Vazquez MV, Desanchez SR, Calvo EJ, Schiffrin DJ. The Electrochemical Reduction of Oxygen on Polycrystalline Copper in Borax Buffer. J Electroanal Chem. 1994;374:189-97.

[55] Cere S, Vazquez M, de Sanchez SR, Schiffrin DJ. Surface redox catalysis and reduction kinetics of oxygen on copper-nickel alloys. J Electroanal Chem. 2001;505:118-24.

[56] Jiang I, Brisard GM. Determination of the kinetic parameters of oxygen reduction on copper using a rotating ring single crystal disk assembly (RRDCu(h k I)E). Electrochim Acta. 2007;52:4487-96.

[57] Brisard G, Bertrand N, Ross PN, Markovic NM. Oxygen reduction and hydrogen evolution-oxidation reactions on $\mathrm{Cu}(\mathrm{hkl})$ surfaces. J Electroanal Chem. 2000;480:219-24.

[58] Lim DH, Wilcox J. Mechanisms of the Oxygen Reduction Reaction on Defective Graphene-Supported Pt Nanoparticles from First-Principles. J Phys Chem C. 2012;116:3653-60.

[59] Stamenkovic VR, Mun BS, Arenz M, Mayrhofer KJJ, Lucas CA, Wang G, et al. Trends in electrocatalysis on extended and nanoscale Pt-bimetallic alloy surfaces. Nat Mater. 2007;6:241-7. 
[60] Lu Y, Jiang Y, Gao X, Wang X, Chen W. Strongly Coupled Pd Nanotetrahedron/Tungsten Oxide Nanosheet Hybrids with Enhanced Catalytic Activity and Stability as Oxygen Reduction Electrocatalysts. J Am Chem Soc. 2014;136:11687-97.

[61] Cai Y, Adzic RR. Platinum Monolayer Electrocatalysts for the Oxygen Reduction Reaction: Improvements Induced by Surface and Subsurface Modifications of Cores. Adv Phys Chem. 2011;2011:1-16.

[62] Dahal A, Batzill M. Graphene-nickel interfaces: a review. Nanoscale. 2014;6:2548.

[63] Liu K, Kang XW, Zhou $Z Y$, Song $Y$, Lee $L$, Tian D, et al. Platinum nanoparticles functionalized with acetylene derivatives: Electronic conductivity and electrocatalytic activity in oxygen reduction. J Electroanal Chem. 2013;688:143-50. 